REVISTA DE DERECHO UNED, NÚM. 8, 2011

\title{
SISTEMATIZACIÓN DE LAS CAUSAS DE INADMISIÓN DEL RECURSO DE CASACIÓN CIVIL
}

\author{
Ma ARÁNZAZu DEL Rincón RUBio
}

Abogada

Resumen: En este trabajo se propone y analiza una sistematización de las causas legales de inadmisión del recurso de casación civil en tres grandes bloques: resoluciones no recurribles en casación, preparación defectuosa del recurso e incorrecta interposición del mismo.

Abstract: In this work it proposes and analyzes a systematizing of the legal reasons of unadmission of the resource of civil cassation in three big blocks: resolutions not recurribles in cassation, defective preparation of the resource and incorrect interposition of the same one.

Palabras clave: Recurso de casación, Tribunal Supremo.

Key words: Resource of cassation, Supreme Court.

Sumario: Introducción. I.- Resoluciones no recurribles en casación. II.- Improcedente o defectuosa preparación del recurso de casación. III.- Defectuosa interposición del recurso de casación.

\section{INTRODUCCIÓN}

El artículo 483 de la LEC, en su apartado $2^{\circ}$, dispone que «procederá la inadmisión del recurso de casación:

$1^{\circ} \mathrm{Si}$, pese a haberse tenido por preparado el recurso, éste fuere improcedente, por no ser recurrible la sentencia o por cualquier defecto de forma no subsanable en que se hubiese incurrido en la preparación. 
$2^{\circ}$ Si el escrito de interposición del recurso no cumpliese los requisitos establecidos, para los distintos casos, en esta Ley.

$3^{\circ} \mathrm{Si}$ el asunto no alcanzase la cuantía requerida, o no existiere interés casacional por inexistencia de oposición a doctrina jurisprudencial, por falta de jurisprudencia contradictoria o si la norma que se pretende infringida llevase vigente más de cinco años o, a juicio de la Sala, existiese doctrina jurisprudencial del Tribunal Supremo sobre dicha norma o sobre otra anterior de contenido igual o similar».

El catálogo de causas de inadmisión es, según un amplio sector de la doctrina ${ }^{1}$, al que nos adherimos, asistemático, dado que las causas comprendidas en los apartados $1^{\circ}$ y $2^{\circ}$ comprenden, sin lugar a dudas, los dos supuestos recogidos en el apartado $3^{\circ}$, que, en consecuencia, son claramente reiterativos. Por ello, proponemos al lector una sistematización de las causas de inadmisión legalmente previstas y que agrupamos en los siguientes tres grandes bloques: resoluciones no recurribles en casación, preparación defectuosa del recurso e incorrecta interposición del mismo.

\section{RESOLUCIONES NO RECURRIBLES EN CASACIÓN}

En primer lugar, se inadmitirá el recurso cuando la sentencia no sea recurrible en casación, lo que hace preciso examinar si la sentencia se encuentra en alguno de los casos del artículo 477.2 de la LEC, conforme a los estrictos criterios fijados por el TS en el Acuerdo de 12 de diciembre de 2000. Señala el artículo 477.2:

«Serán recurribles en casación las sentencias dictadas en segunda instancia por las Audiencias Provinciales, en los siguientes casos:

$1^{\circ}$ Cuando se dictaran para la tutela judicial civil de derechos fundamentales, excepto los que reconoce el artículo 24 de la Constitución.

$2^{\circ}$ Cuando la cuantía del asunto excediere de 150.000 euros.

$3^{\circ}$ Cuando la resolución del recurso presente interés casacional (...)».

${ }^{1}$ Entre otros, Montero Aroca, J. y Flors MatíEs, J., «El recurso de casación civil (casación e infracción procesal)», Valencia, Tirant lo Blanch, 2009, pág. 547, y LoREDo Colunga, M., «La casación civil. El ámbito de recurso y su adecuación a los fines casacionales», Valencia, Tirant lo Blanch, 2004, pág. 250. 
Por consiguiente, atendiendo al órgano del que proceden, se excluyen de la casación las sentencias dictadas por los Juzgados de Primera Instancia, tanto las dictadas en primera instancia (desaparece, pues, la llamada casación per saltum) como las dictadas al conocer del recurso de apelación contra las de los Juzgados de Paz.

También se excluyen de este recurso extraordinario las sentencias dictadas por la Sala de lo Civil y Penal de los Tribunales Superiores de Justicia o por la Sala $1^{\text {a }}$ del TS cuando conocen de procesos civiles en primera o única instancia (por ejemplo, las demandas de responsabilidad civil contra magistrados y aforados).

Asimismo, atendiendo al tipo de resolución, se inadmitirá la casación cuando la resolución que se pretenda recurrir sea un auto o «cuando debió adoptar esa forma» (dice el Acuerdo de 12-12-2000), por cuanto suelen ser de contenido procesal y no deciden el fondo del asunto (ex art. 206.2.2 $2^{\text {a }}$ LEC), así como las sentencias dictadas en grado de apelación que no pusieren fin a la primera instancia tras la tramitación completa del procedimiento, v.gr. las resoluciones dictadas en materia de declinatorias, nulidad de actuaciones, impugnaciones de costas, tercerías de dominio, medidas cautelares y, en general, las dictadas al resolver cuestiones incidentales -tómese el término en sentido amplio- tales como oposiciones a juras de cuentas, impugnaciones de cuadernos particionales, inadmisión o exclusión de bienes en la liquidación de la sociedad de gananciales, etc.

Excepcionalmente, se admite la casación (y por la vía del interés casacional) respecto de los autos dictados en grado de apelación en el procedimiento de reconocimiento y ejecución de sentencias extranjeras, al amparo del Convenio de Bruselas de 27 de diciembre de 1968, del Convenio de Lugano de 16 de septiembre de 1988 y de los Reglamentos de la UE núms. 2201/2003 (por el que se deroga el anterior 1347/2000) y 44/2001.

Entrando ya en el estudio de los tres apartados del artículo 477.2 LEC, en cuanto al primero de ellos relativo a la vía judicial de amparo ordinario previa al recurso de amparo constitucional prevista en el artículo 249.1.2 $2^{\circ}$ de la LEC, se inadmitirá el recurso cuando se trate de vulneraciones de otros derechos constitucionales no fundamentales, como por ejemplo, la protección a la familia del artículo $39 \mathrm{CE}^{2}$, el derecho a una vivienda digna del artículo $47 \mathrm{CE}^{3}$ o el muy frecuentemente invocado derecho de propiedad del artículo $33 \mathrm{CE}^{4}$.

\footnotetext{
${ }^{2}$ Ver el ATS de 30/12/2003, RJ 2004/620.

${ }^{3}$ Ver el ATS de 27/01/2004, RJ 2004/1913.

${ }^{4}$ Ver el ATS de 31/07/2003, RJ 2003/214915.
} 
Por la misma razón, tampoco tienen acceso por el cauce del artículo 477.2.1 ${ }^{\circ}$ LEC (pero sí podrían por la vía del interés casacional) las sentencias dictadas en procesos en los que se ejercite el derecho de rectificación, por cuanto el mismo no tiene carácter de fundamental y sí y sólo carácter instrumental de la protección de otros derechos fundamentales ${ }^{5}$.

Por supuesto, también se inadmitirá la casación cuando se trate de combatir vulneraciones de cualesquiera manifestaciones del derecho a la tutela judicial efectiva del artículo 24 de la CE, que serán objeto del recurso extraordinario por infracción procesal.

En segundo lugar, en cuanto a la summa gravaminis, el Acuerdo de 12 de diciembre de 2000 dice que «el núm. 2 del art. 477.2 de la LEC debe enlazarse con los arts. 249.2 y 250.2 LEC, por lo que serán recurribles las sentencias recaídas en juicio ordinario, en relación con demandas cuya cuantía exceda de veinticinco millones de pesetas, quedando excluidas las dictadas en juicio ordinario de cuantía inferior o indeterminada, así como en el verbal».

La consecuencia de ello es que por la vía del ordinal $2^{\circ}$ del art. 477.2 sólo pueden recurrirse en casación los procedimientos tramitados por razón de la cuantía (no los tramitados ratione materiae aun cuando el interés del pleito excediere de $150.000 €$ ) y, si aquéllos -los tramitado por razón de la cuantía- no superan la cifra de los $150.000 €$, no podrán ya tener acceso a la casación, aunque las sentencias que les pongan fin resuelvan contrariamente a la doctrina jurisprudencial del TS o a la de otras Audiencias Provinciales.

A propósito de esta cuestión, hemos de recordar que el TS viene admitiendo el acceso a la casación -bien que como «supuesto particular» o «excepcional caso»- cuantías «relativamente indeterminadas» o «indeterminadas en principio» en asuntos en los que existen datos suficientes como para deducir que, pese a la inconcreción cuantitativa, se excede con creces los 150.000 euros $^{6}$. Sin embargo, en el otro extremo, no podemos dejar de mencionar los casos en los el TS veda el acceso a la casación no ya a los asuntos cuya cuantía es exactamente de 150.000 euros (que ciertamente «no exceden» de dicha suma) sino también a los de 25.000.000 Ptas. justos y cuya matemática equivalencia en euros asciende a 150.253,03 €, lo que se

\footnotetext{
${ }^{5}$ Véase, el ATS de 31/07/2007, JUR 2007/267632.

${ }^{6}$ Véanse los Autos del TS de 16/07/2002, RJ 2002/7825, de 28/01/2003, RJ 2003/823, de 22/02/2005, RJ 2005/2442 y de 07/11/2006, RJ 2006/7135.
} 
nos antoja verdaderamente incomprensible, más allá de los razonamientos «jurídicos» de nuestro Alto Tribunal ${ }^{7}$.

En tercer y último lugar, dice el Acuerdo de 12 de diciembre de 2000 que «el núm. 3 del art. 477.2 de la LEC ha de concordarse con los arts. 249.1 (excepto su núm. 2) y 250.1 de la LEC, de manera que las sentencias recaídas en juicio ordinario, por razón de la materia, excepto los de tutela civil de los derechos fundamentales, y en juicio verbal, igualmente en atención a la materia, así como las sentencias dictadas en los procesos especiales regulados en el Libro IV de la LEC, en otros procedimientos especiales de la propia LEC y en materia de reconocimiento y ejecución de sentencias extranjeras, al amparo de los Convenios de Bruselas y Lugano, habrán de ser recurridas por la vía de este ordinal tercero, lo que hace preciso que la resolución del recurso de casación presente «interés casacional».

En definitiva, el TS afirma el carácter exclusivo y excluyente de los supuestos previstos en el artículo 477.2 LEC y su conexión con los distintos tipos de procedimiento, de manera que los asuntos tramitados por razón de la cuantía sólo puedan acceder a la casación por exceder de 150.000 euros y los tramitados ratione materiae sólo puedan recurrirse si presentan «interés casacional». No compartimos los argumentos empleados por el Alto Tribunal para sostener esta particular interpretación de las normas de la LEC (en síntesis, la coincidencia de la mens legis y la mens legislatoris), sin embargo, sí parece defendible la afirmación de que «si fuera posible que los asuntos tramitados en razón a la cuantía (inferior a veinticinco millones de pesetas) pudieran también tener acceso a la casación acreditando el interés casacional, la única causa de inadmisión aplicable sería la inexistencia de dicho presupuesto y nunca la insuficiente valoración económica del litigio que, por si misma, jamás vedaría el recurso de casación $»^{8}$. Ello no obstante, la función unificadora del recurso de casación debería poder alcanzarse mediante la posibilidad de revisar todos los asuntos civiles y mercantiles que presenten interés casacional, incluidos los tramitados por razón de la cuantía -supere o no ésta los 150.000 euros- si presentan dicho interés.

Consideramos que, acertados o no los criterios fijados por el TS en el Acuerdo de 12-12-2000, lo cierto es que no dicen los mismo que

${ }^{7}$ Es el caso del ATS de 07/10/2003, RJ 2003/8676 y el del ATS de 06/02/2007, JUR 2007/59048, calificado por XIOL RIOS, J.A. («Enjuiciamiento Civil. Comentarios y Jurisprudencia», Tomo II, Las Rozas, Madrid, Sepin, 2009, pág. 3.210) como «caso curioso".

${ }^{8}$ Véase el ATS de 12/02/2008, JUR 2008/105591. 
dice la letra de la Ley de Enjuiciamiento Civil, de ahí que no sea extraño que en el Auto del Tribunal Constitucional 191/2004, de 26 de mayo, rec. 244/2002, EDJ 2004/267093, tanto el Ministerio Fiscal como el Magistrado D. Eugeni Gay Montalvo -que disintió de la opinión mayoritaria de la Sala formulando un valiente Voto Particular- sostuvieran que la expresada interpretación sistemática realizada por el TS pudiera no superar el canon de la razonabilidad de las decisiones relativas a la inadmisión del recurso, dado su rigorismo formal y habida cuenta que no se sustenta en una causa específicamente prevista en la LEC, por cuanto que la ley define el «interés casacional» sin hacer referencia alguna al tipo de proceso en que se dicte la sentencia. Críticas a parte, lo cierto es que el TC en la Sentencia ${ }^{\circ}$ 108/2003, de 2 de junio (rec. 82/2002, Pte.: Jiménez Sánchez, Guillermo, EDJ 2003/15661) ha dicho, respecto de la interpretación contenida en el Acuerdo del TS de 12 de diciembre de 2000, que «ha integrado la regulación de la Ley de enjuiciamiento civil de modo que forma parte de la normativa sobre el recurso de casación».

La prueba definitiva de lo discutible de la argumentación del TS es que los Tribunales Superiores de Justicia de Cataluña, de Navarra, de Aragón y de Valencia han desoído a estos efectos los criterios acordados en la Junta General de 12 de diciembre de 2000. Véanse, entre otras muchas, la STSJ de la Comunidad Valenciana núm. 10/2003, de 29 de mayo, Recurso de Casación núm. 2/2003 (RJ 2003/4420, Pte.: Juan Montero Aroca); la STSJ de Navarra núm. 40/2003, de 26 de septiembre, Recurso de Casación núm. 85/2002 (RJ 2003/8685, Pte.: D. Alfonso Otero Pedrouzo); o las SSTSJ de Catalunya de 21 de octubre de 2002 y de 19 de julio de 2004.

\section{IMPROCEDENTE O DEFECTUOSA PREPARACIÓN DEL RECURSO DE CASACIÓN}

En este epígrafe procedemos a analizar, en primer lugar, un conjunto de supuestos de incumplimiento de los requisitos procesales subjetivos y de la actividad, tales como: (i) la presentación del escrito ante órgano incompetente (según el artículo 479 LEC que «el recurso de casación se preparará mediante escrito presentado ante el tribunal que hubiere dictado la sentencia», esto es, ante la Audiencia Provincial); (ii) la falta de representación o incumplimiento del requisito de postulación; (iii) la falta de defensa técnica; (iv) la presentación del escrito fuera del plazo de cinco días previsto en el artículo 479 LEC, plazo especialmente escueto -según veremos- en el supuesto de que 
se prepare el recurso por la vía del interés casacional ${ }^{9}$; (v) la omisión del traslado de copias, ex artículo 276 LEC; (vi) por carecer el recurrente de la condición de parte; (vii) falta de legitimación del recurrente por no afectarle desfavorablemente la resolución impugnada, de conformidad con lo dispuesto en el artículo 448 de la LEC.

Los tres primeros defectos (presentación del escrito ante órgano incompetente y falta de representación y falta de defensa letrada) son subsanables, por consiguiente, la inadmisión del recurso de casación en estos casos sólo se producirá cuando la parte no proceda a su subsanación en el plazo que a tal efecto le conceda el Tribunal. Los restantes casos que hemos mencionado no son subsanables, por lo que determinarán la automática inadmisión del recurso.

Un segundo grupo de supuestos de preparación defectuosa del recurso de casación son los derivados del incumplimiento de los requisitos especiales previstos en el artículo 449 de la LEC, a cuyo tenor es preciso acreditar al preparar el recurso: (i) en los procesos que lleven aparejado el lanzamiento, tener satisfechas las rentas vencidas; (ii) en los procesos en que se pretenda la condena a indemnizar los daños y perjuicios derivados de la circulación de vehículos de motor, haber constituido depósito del importe de la condena más los intereses y recargos exigibles; (iii) y en los procesos en que se pretenda la condena al pago de las cantidades debidas por un propietario a la comunidad de vecinos, tener satisfecha o consignada la cantidad líquida a que se contrae la sentencia condenatoria.

En estos casos, la falta de cumplimiento en plazo del pago, la consignación o el depósito anteriormente aludidos constituye un defecto insubsanable, mas la mera falta de acreditación documental de los anteriores hechos será subsanable en el plazo que a tal efecto conceda el tribunal.

Pero, sin duda, el grupo de causas de inadmisión más interesante es la que engloba los distintos supuestos de incumplimiento de los requisitos de fondo o de contenido del escrito de preparación, de entre los cuales hemos de comenzar por aludir a la utilización de una vía no idónea de acceso a la casación de entre las tres mencionadas en el

\footnotetext{
${ }^{9}$ Coincidimos con Loredo Colunga, M. («La casación civil. El ámbito de recurso y su adecuación a los fines casacionales», Valencia, Tirant lo Blanch, 2004, pág. 239) y con LóPEz SÁNCHEZ, J. ( LLos Recursos Extraordinarios por Infracción Procesal y de Casación», Navarra, Thomson Aranzadi, 2004, pág. 311) en que es un tiempo limitado en exceso y en absoluto razonable para la complejidad exigida por el TS para esta clase de escrito de preparación.
} 
artículo 477.2 LEC, habida cuenta el carácter excluyente de los tres supuestos y la conexión que el TS hace entre cada uno de ellos y la clase de procedimiento tramitado (procedimiento ordinario del artículo $249.1 .2^{\circ}$, procedimientos sustanciados por razón de la cuantía y los sustanciados ratione materiae), en los términos expuestos en el anterior epígrafe I.

Aun cuando el Acuerdo del TS de 12-12-2000 señaló que los casos previstos en los tres ordinales del art. 477.2 de la LEC «constituyen supuestos distintos y excluyentes, por lo que sólo cabrá solicitar la preparación al amparo de uno de ellos y el tribunal no podrá reconducir a otro distinto del invocado por la parte», lo cierto es que es frecuente en la práctica intentar la recurribilidad de la sentencia por distintas vías de acceso enunciadas de forma acumulada, subsidiaria o alternativa ${ }^{10}$, amén de que el propio TS ha moderado el alcance de tal afirmación, pues ha venido admitiendo que la omisión o la cita errónea del ordinal concreto no ha de constituir un obstáculo insalvable para el acceso al recurso si se cumplen los restantes requisitos exigidos al efecto, permitiendo reconducir la invocación equivocada del ordinal $3^{\circ}$ del art. 477.2 -interés casacional-al ordinal $2^{\circ}$ (si la cuantía del asunto supera los $150.000 €$ ), aunque no al revés (no puede el tribunal reconducir la cita errónea del ordinal $2^{\circ}$ al ordinal $3^{\circ}$ porque no habrá acreditado el recurrente el presupuesto de recurribilidad del interés casacional en el preclusivo plazo de cinco días y, su eventual justificación posterior, sería extemporánea).

Otra causa de inadmisión del recurso mencionado en el Acuerdo de 12-12-2000 es la falta de indicación de la infracción legal que se considere cometida (ya sea por aplicación incorrecta, por falta de aplicación o por aplicación indebida) y, toda vez que el motivo único del recurso de casación ex art. 477, apdo. $1^{\circ}$ LEC es «la infracción de normas aplicables para resolver las cuestiones objeto del proceso», las cuales han de ser necesariamente normas sustantivas de carácter civil o mercantil, se excluirá la casación cuando se invoquen infracciones de: (i) normas procesales (con la amplitud con que ha sido configurado el objeto del recurso extraordinario por infracción procesal, más allá de los óbices procesales del artículo 416 LEC); (ii) normas

${ }^{10}$ Así lo afirman Sospedra Navas, F. J, (Coord.) («Tratado práctico del proceso civil», Tomo II, Navarra, Thomson Civitas, 2008, pág. 656) y MoNTERo AROCA, J. («El recurso de casación civil ...», pág. 458). En contra, GisBert PomATA, M. (en la «Revista de Derecho Procesal», 2007, Estudio jurisprudencial sobre la admisibilidad del recurso de casación, pág. 364) sostiene que no admiten los Tribunales «que se aleguen dos o los tres ordinales de forma alternativa o subsidiaria». 
penales, fiscales o administrativas (aunque sí se admiten cuando sean complementarias de una norma civil o estén íntimamente relacionadas con ésta); y (iii)normas con rango inferior a la ley, salvo que sea un reglamento de desarrollo de una ley o norma con rango de ley o tenga carácter de norma complementaria de la ley. Asimismo, en la casación de que conoce el TS, tampoco podrá invocarse la infracción de una norma de Derecho civil Foral o Especial.

Por su carácter de norma legal, se admite la casación fundada en preceptos constitucionales (ex art. 5.4 de la LOPJ), a excepción del artículo $24 \mathrm{CE}$, así como en la infracción de Tratados Internacionales ratificados y en la normativa comunitaria. Asimismo, por ser fuentes del Derecho se admitirá la casación por infracción de la costumbre y los principios generales del Derecho, pero en los concretos términos del artículo 1, apartados 3 y 4 del CC. Sin embargo, ha desaparecido en la vigente LEC, como motivo autónomo y propio de los recursos extraordinarios, la infracción de la doctrina jurisprudencial, lo que no impide que fundados éstos en infracciones de normas jurídicas, se justifique o fundamente esa infracción normativa en la interpretación que la Jurisprudencia hace del concreto precepto invocado, toda vez que la Jurisprudencia no tiene valor de ley ni carácter de fuente del Derecho y sólo «complementa» el ordenamiento, ex art. 1.6 CC.

El TS ha subrayado en no pocas ocasiones que la mención de la infracción legal que se considera cometida es absolutamente esencial y, su omisión, no puede ser subsanada por la parte a través del recurso de reposición preparatorio al de queja ni en un improbable escrito de interposición posterior.

Por otra parte, hemos de advertir que la técnica casacional exige que la cita del precepto infringido sea clara y precisa, que se mencionen separadamente cuantas infracciones distintas se invoquen y que estén referidas a la materia objeto del proceso (lo que permitirá que el TS realice admisiones parciales del recurso) y, que si el precepto invocado consta de varios párrafos o apartados, que se individualice el concreto apartado que se considere vulnerado. Consecuentemente, constituyen supuestos de preparación defectuosa la cita conjunta de preceptos heterogéneos, la cita conjunta de preceptos sustantivos y procesales y, en general, cuantos defectos venía advirtiendo a este respecto la Jurisprudencia sentada en relación a la anterior LEC de 1881.

Si el requisito en estudio no plantea problemas en caso de prepararse la casación por la vía de los ordinales $1^{\circ}$ y $2^{\circ}$ del artículo 477.2 de la LEC (con la particularidad de que, en el primer caso, la infrac- 
ción legal cometida consistirá en la cita del Derecho Fundamental que se dice vulnerado), el escrito de preparación devendrá harto complicado si se pretende la casación por la vía del interés casacional, sobre todo porque el TS ha exacerbado por vía interpretativa los requisitos exigidos en este caso, lo que nos obliga a referirnos una vez más al Acuerdo de 12-12-2000, distinguiendo los tres supuestos tasados de «interés casacional»:

1).--Por oposición a la doctrina jurisprudencial del Tribunal Supremo.

Según el meritado Acuerdo es «necesario citar dos o más sentencias de la Sala Primera, razonándose cómo, cuándo y en qué sentido ha sido vulnerada la doctrina de cada una de ellas» y «la preparación defectuosa será apreciable al omitirse la expresión de las sentencias de la Sala Primera, y también cuando se mencionen éstas y su contenido, pero no se razone la vulneración de su doctrina por la resolución recurrida, lo que resulta imprescindible para que la Audiencia pueda examinar el supuesto de recurribilidad invocado y decidir sobre la preparación del recurso de casación».

Cualesquiera citas que no se ajusten al estricto patrón marcado por el TS, serán objeto de inadmisión por defectuosa preparación del recurso: ya sea porque sólo se cita una Sentencia del TS, ya sea porque aun citándose varias no se explique cómo, cuándo y en qué sentido se vulnera la doctrina jurisprudencial relativa a la concreta infracción legal alegada. El TS ha insistido en que tales defectos son insubsanables.

Tan sólo en un punto el TS se ha pronunciado con cierta «benevolencia» (y contrariamente a lo que veremos a continuación en el supuesto de «jurisprudencia» contradictoria de las Audiencias Provinciales): basta la cita argumentada de las Sentencias de la Sala Primera «aunque no vengan referidas a un supuesto sustancialmente idéntico al examinado -requisito éste que no cabe exigir cuando se alegue vulneración a la jurisprudencia del Tribunal Supremo, pues lo relevante, en estos casos, es la oposición a la misma».

2).--Por existir jurisprudencia contradictoria de las Audiencias Provinciales.

Dice el Acuerdo de 12-12-2000 que «por tal debe entenderse la relativa a un punto o cuestión jurídica, sobre el que exista un criterio dispar entre Audiencias Provinciales o Secciones orgánicas de la misma o diferentes Audiencias, exigiéndose dos sentencias firmes de uno de esos órganos jurisdiccionales, decidiendo en sentido contrario 
al contenido en el fallo de otras dos sentencias también firmes de diferente tribunal de apelación, por lo cual la diversidad de respuestas judiciales, en razón a fundamentos de derecho contrapuestos, debe producirse en controversias sustancialmente iguales, lo que requiere expresar la materia en que existe la contradicción y de qué modo se produce ésta, así como exponer la identidad entre cada punto resuelto en la sentencia que se pretende recurrir y aquél sobre el que existe la jurisprudencia contradictoria que se invoca».

«La preparación defectuosa concurrirá cuando se prescinda de mencionar las sentencias firmes de Audiencias Provinciales, que deberán ser dos de un mismo órgano jurisdiccional y otras dos de otro órgano diferente, siendo rechazable la enumeración masiva de resoluciones, que habrán de limitarse a cuatro por cada punto de cuestión o contradicción (dos en cada sentido) y, en el caso de citarse más, se estará a las de fecha más reciente; asimismo será necesario recoger el contenido de las sentencias, su ratio decidendi, con expresión de la específica materia en que se suscita la contraposición jurisprudencial y de qué modo se produce, siendo preciso razonar sobre la identidad de supuestos entre la sentencia recurrida y las que se invoquen como contradictorias entre sí, lo que igualmente resulta imprescindible para que la Audiencia efectúe el control de recurribilidad que le corresponde en la fase preparatoria».

Esta es, sin duda, la modalidad de escrito de preparación más difícil y rigurosa y la que más inadmisiones y denegaciones está generando en la práctica, toda vez que cualesquiera citas jurisprudenciales diferentes al esquema "dos de un mismo órgano jurisdiccional y otras dos de otro órgano diferente» son irremediablemente rechazadas por el TS (por ejemplo, porque se citen menos de cuatro sentencias, o porque no haya dos sentencias de contraste sino sólo una, o porque no se razone suficientemente el punto concreto de la contradicción jurídica o la identidad de supuestos fácticos, o porque se haya relacionado un amplio listado de sentencias contradictorias pero procedentes de distintas Audiencias y no pueda inferirse el "antagonismo reiterado» o consolidación jurisprudencial del que habla el TS, etc). Quizá una de las inadmisiones por preparación defectuosa más sangrante es la referida en el ATS de 9 de diciembre de 2003 (RJ 2003/9326, Pte.: Pedro González Poveda), en el que se rechazó la invocación dos sentencias de una misma Audiencia Provincial (la de Barcelona) y otras dos sentencias de distinta Audiencia (la de Santa Cruz de Tenerife) por no haber acreditado el recurrente que procedieran de la misma Sección orgánica de cada una de tales Audiencias. Y, como no podía ser de otro modo, estas pre- 
paraciones defectuosas del artículo 483.1 inciso $2^{\circ}$ LEC son insubsanables.

3).-Cuando se apliquen normas de vigencia inferior a cinco años y no exista jurisprudencia relativa a normas anteriores.

En este caso el Acuerdo de 12-12-2000 indica que «deberá el recurrente identificar la disposición legal, y comprobarse en fase de preparación el plazo de cinco años entre la entrada en vigor de la norma y la fecha de la sentencia recurrida», teniendo en cuenta que «el cómputo debe efectuarse tomando como dies a quo la fecha de su entrada en vigor, mientras que el dies ad quem será la fecha en que se dicte la sentencia recurrida» ${ }^{11}$.

\section{DEFECTUOSA INTERPOSICIÓN DEL RECURSO DE CASACION}

En este epígrafe podemos analizar, en primer lugar, un conjunto de supuestos de incumplimiento de los requisitos procesales subjetivos y de la actividad del escrito de interposición, tales como: (i) la presentación del escrito ante órgano incompetente (según el artículo 481 LEC dicho escrito ha de presentarse «ante el tribunal que hubiere dictado la sentencia», esto es, ante la Audiencia Provincial); (ii) la falta de representación o incumplimiento del requisito de postulación; (iii) la falta de defensa técnica; (iv) la omisión del traslado de copias, ex artículo 276 LEC; (v) la presentación del escrito fuera del plazo de veinte días previsto en el artículo 481 LEC; (vi) la falta de legitimación del recurrente por no afectarle desfavorablemente la resolución impugnada, de conformidad con lo dispuesto en el artículo 448 de la LEC.

Los cuatro primeros defectos (presentación del escrito ante órgano incompetente, falta de representación y de defensa letrada y la omisión del traslado de copias) son subsanables, por consiguiente, la inadmisión del recurso de casación en estos casos sólo se producirá cuando la parte no proceda a su subsanación en el plazo que a tal efecto le conceda el Tribunal. Los restantes casos que hemos mencionado no son subsanables, por lo que su concurrencia determinará la automática inadmisión del recurso.

${ }^{11}$ En cuanto al díes ad quem, un sector minoritario de la doctrina (XIOL Ríos, J. A., «Enjuiciamiento Civil. Comentarios y Jurisprudencia», pág. 3.216, que cita a Romero NAVARRO) se aparta del criterio del TS al considerar que por tal ha de entenderse la «fecha en que se interpone el pleito en primera instancia». 
Otro defecto que provocará la inadmisión del recurso de casación es la falta de acreditación del pago de la Tasa Judicial (el modelo 696 de «Autoliquidación de la tasa por ejercicio de la función jurisdiccional») que han de abonar las personas jurídicas no exentas de su pago. Su omisión es subsanable y quienes pleiteamos estamos acostumbrados a que se nos conceda un plazo de diez días para aportar el modelo 696 no acompañado con anterioridad.

Un segundo grupo de supuestos de interposición defectuosa del recurso de casación son los relativos a la falta de aportación de la documentación exigida, debiendo citarse a este respecto dos casos absolutamente absurdos por lo superfluo de la exigencia: la no aportación de la certificación de la sentencia impugnada (artículos 481.2 y 482.2 LEC) y la no aportación del «texto de las sentencias que se aduzcan como fundamento del interés casacional» (artículo 481.2 LEC). Respecto del primero de ellos, a nadie se le oculta que, si que "presentado el escrito de interposición, dentro de los cinco días siguientes se remitirán todos los autos originales al tribunal competente para conocer del recurso de casación...» (artículo 482.1 LEC), es evidente que aunque el recurrente no hubiera pedido (mediante otrosí en el escrito de preparación) que le fuera expedida por el Secretario de la Audiencia la correspondiente certificación de la sentencia impugnada o, aunque solicitada, no hubiera sido expedida en el plazo de los veinte días para interponer el recurso, el original de la sentencia ya obrará incorporada en el rollo de actuaciones que ha de remitirse a la Sala $1^{\text {a }}$ del TS.

En cuanto a la no aportación del «texto de las sentencias que se aduzcan como fundamento del interés casacional», hemos entrecomillado el texto literal del artículo 481.2 LEC para demostrar que, una vez más el TS ha ido más allá de lo que la norma exige, pues califica el Acuerdo de 12 de diciembre de 2000 como supuesto de interposición defectuosa «que no se presente el texto completo de las sentencias de las Audiencias Provinciales que se aduzcan como fundamento del interés casacional, mediante certificación íntegra de las mismas expedida por secretario judicial, con expresión de su firmeza». ¡Esperemos que la falta de estas certificaciones sea subsanable!

El tercer y último grupo de casos de inadmisión del recurso son los constitutivos de incumplimientos de los requisitos de fondo del escrito de interposición, lo que se conoce como falta de una adecuada «técnica casacional», respecto de la cual, resulta plenamente aplicable a la nueva legalidad toda una consolidada Jurisprudencia recaída en torno al artículo 1.707 de la derogada LEC de 1881. 
Si como dice el artículo 481.1 LEC en el escrito de interposición se han de exponer "con la necesaria extensión, sus fundamentos», será causa de inadmisión del recurso no exponer, con la suficiente extensión o con la debida claridad y precisión, los fundamentos del recurso, esto es, las infracciones normativas que se adujeron como motivos del mismo, o como dice el Acuerdo de 12-12-2000 «que no se expongan con la necesaria extensión los fundamentos del recurso, en orden a la infracción de normas aplicables para resolver las cuestiones objeto del proceso (art. 481.1 en relación con el art. 477.1 de la LEC)».

Como casos de interposición defectuosa del recurso por falta de técnica casacional podrían citarse, con apoyo en los numerosísimos Autos de inadmisión del recurso, los siguientes:

— «Falta de claridad manifiesta en la motivación del recurso o el confusionismo en su exposición, que puede venir dado por la cita acumulada en un solo motivo de preceptos legales heterogéneos (SSTS 29-6-93 [RJ 1993, 5333], 21-7-93, 11-3-96 [RJ 1996, 2416], 285-96 [RJ 1996, 3859], 22-1-97 [RJ 1997, 119], 26-2-99 [RJ 1999, 1061] , 1-3-99 [RJ 1999, 1356], 25-1-2000 [RJ 2000, 350] y 23-2-2000 [RJ 2000, 755]), por la mezcla indiscriminada de cuestiones de hecho (ahora ajenas al recurso de casación y propias del recurso extraordinario por infracción procesal), u otras procesales, y de derecho en un mismo motivo (SSTS 27-11-91, 27-2-92 [RJ 1992, 1246] , 22-10-92 [RJ 1992, 8598], 29-6-93 [RJ 1993, 5333], 12-9-96 (sic) [RJ 1996, 8946], 18-4-97 [RJ 1997, 3247], 11-5-2000 [RJ 2000, 3108] y 29-52000 [RJ 2000, 3922]) o por la falta de separación entre los motivos invocados, a cada uno de los cuales deben corresponder unos razonamientos diferentes sobre su pertinencia y fundamentación (SSTS 912-94 [ RJ 1994, 9434], 17-11-95 [RJ 1995, 8262] y 6-10-2000 [RJ $2000,8804]$ ), doctrina que bajo el nuevo régimen de la casación ha de aplicarse al desarrollo en la interposición de cada una de las infracciones legales expresadas en el escrito de preparación, siendo igualmente doctrina constante y reiterada de esta Sala que la naturaleza extraordinaria del recurso de casación, ajena a lo que sería una tercera instancia, no permite la cita masiva de preceptos en un mismo motivo, o apartado en que se articule el recurso, como cuando se utiliza la fórmula «... y siguientes», ni fundar el recurso en la infracción de preceptos heterogéneos (SSTS 2-6-95 [RJ 1995, 4594], 11-3-96 [RJ 1996, 2416] , 28-5-96 [RJ 1996, 3859]».

Así lo razona el ATS de 17 de enero de 2006 (RJ 2006/269, Pte.: Román García Varela), añadiendo que en absoluto procede «so pena 
de originar un riesgo de indefensión para la parte contraria, subsanar de oficio las manifiestas deficiencias del motivo, y puesto que el recurso de casación no es una tercera instancia el escrito de interposición no puede equipararse a un escrito de alegaciones (SSTS 165-95 [RJ 1995, 3921] y 5-3-97 [RJ 1997, 1649], entre otras muchas), traduciéndose la exigencia de claridad en la formulación del recurso de casación en una obligación insoslayable del recurrente (SSTS $17-3,25-4$ [RJ 1985, 1811] y 24-5-85 [RJ 1985, 2392] y 9-12-85 [RJ $1985,6426]$ ) sin que quepa ignorar el rigor formal que es exigible en vía casacional, dado el carácter extraordinario del recurso de casación, e incluso, a tal respecto, ha de señalarse que el Tribunal Europeo de Derechos Humanos, en su sentencia de 19 de diciembre de 1997 (TEDH 1997, 2) (caso Brualla Gómez de la Torre contra España), se pronunció sobre la supuesta violación del Convenio por un Auto de inadmisión de esta Sala, rechazando que tal violación se produjera, y también declarando admisible un especial formalismo del recurso de casación».

— Supuestos en que el TS denuncia la «artificiosidad del recurso», en aquéllos casos en los que «no se respeta la base fáctica de la Sentencia impugnada, y también la artificiosidad de aquéllos en los que se planteaba en el recurso una cuestión que, amparada en la apariencia generada por el cumplimiento de los requisitos puramente formales, no afectaba a los razonamientos en los que la Audiencia basaba la Sentencia de segunda instancia, planteando así una cuestión jurídica sustantiva que, de resolverse por este Tribunal, no afectaría al fallo perjudicial al recurrente que justifica el recurso, en cuanto la verdadera ratio decidendi resultaba soslayada en el mismo. (...) La defectuosa técnica casacional no sólo es apreciable cuando no se ajustan los razonamientos del recurso a la base fáctica de la Sentencia impugnada o cuando no afectan a su ratio decidendi, también concurre cuando la parte recurrente, olvidando que no se halla ante una tercera instancia, intenta reproducir, sin más, la controversia ante esta sede desde su particular planteamiento, olvidando así que el recurso de casación no constituye una tercera instancia, sino una modalidad de recurso extraordinario, en el que prevalece la finalidad de control de la aplicación de la norma y de creación de doctrina jurisprudencial, lo que exige plantear al Tribunal Supremo cuestiones jurídicas, de un modo preciso y razonado, pero siempre sin apartarse de los hechos, pues no cabe la revisión de la base fáctica de la Sentencia de segunda instancia, como ya se ha dicho, de ahí que el vicio de la "petición de principio" o de hacer "supuesto de la cuestión», continúe determinando inexorablemente la improcedencia del re- 
curso de casación». (ATS de 6 de febrero de 2007, JUR 2007/59006, Pte.: Clemente Auger Liñán).

- Otro supuesto de interposición defectuosa del recurso por falta de técnica casacional es el de introducir en el escrito de interposición, como cuestiones novedosas, la infracción de preceptos no alegados en el previo escrito de preparación. Así lo señala el ATS de 27 de marzo de 2007 (RJ 2007/2060, Pte.: Clmente Auger Liñán), a cuyo tenor: «la necesidad de indicar en el escrito de preparación la infracción legal a que se refiere el art. 479 LEC, exigencia que resulta asimismo precisa para conocer la exacta pretensión impugnatoria, que debe quedar delimitada en la fase inicial del recurso, de modo que en la interposición del mismo se argumentará sobre las vulneraciones normativas que se dejaron especificadas en el escrito preparatorio (o parte de ellas, pero no sobre otras), según se desprende del propio art. 481.1 de la LEC, cuando se refiere a que «se expondrán... sus fundamentos», precepto que necesariamente ha de ponerse en relación con el reiterado art. 479, apartados 2, 3 y 4 de la LEC y que, en correcta técnica casacional, implica plantear al Tribunal Supremo cuestiones jurídicas sustantivas, de un modo preciso y razonado, sin apartarse de los hechos, pero siempre con referencia a las infracciones previamente invocadas en el escrito de preparación (nunca distintas), sin que la omisión de la cita de norma infringida en la preparación sea subsanable a través del escrito de interposición del recurso de casación».

- Finalmente, uno de los supuestos más frecuentes de preparación e interposición defectuosas es la denuncia de infracción de normas procesales, cuestiones que exceden de la casación al pertenecer al ámbito del recurso extraordinario por infracción procesal, a veces encubiertas bajo la cita de preceptos sustantivos como, por ejemplo, los artículos del Código Civil relativos a la interpretación de los contratos, en cuyo caso se inadmite el recurso por su artificiosidad, dado que en el fondo lo que pretende el recurrente es realizar una nueva valoración de la prueba, proscrita en sede casacional.

Por último, no podemos dejar de referirnos al Proyecto de Ley de medidas de agilización procesal publicado en el Boletín Oficial de las Cortes Generales del 18 de marzo de 2011, dado que, en el caso de que finalmente sea aprobado como Ley tras su oportuna tramitación parlamentaria, tendrá una importante incidencia en el asunto que nos ocupa.

Restringiéndonos, pues, a las reformas afectantes al recurso de casación, aludiremos en primer lugar a la supresión del trámite de pre- 
paración del recurso, permaneciendo un único trámite de interposición del mismo. Si dicha eliminación parece adecuada en el caso del recurso de apelación por cuanto ninguna ventaja aportaba su anuncio ni para los litigantes ni para la Administración de Justicia, la supresión de la preparación del recurso de casación se nos antoja mayormente acertada, sobre todo cuando el acceso al recurso tenga lugar por la vía del «interés casacional».

En efecto, el exacerbado rigor con el que el TS viene interpretando este presupuesto (más aún en el caso de invocar «jurisprudencia contradictoria de las Audiencias Provinciales») ha dejado casi vacío de contenido el escrito de interposición del recurso a fuerza de exigir, en el trámite de preparación, un ingente número de requisitos casi imposibles de cumplir en el escueto plazo de cinco días. Por consiguiente, tiene sentido establecer un único trámite de interposición en el que se cumplimenten todas las exigencias requeridas en la legalidad vigente para los dos escritos de preparación e interposición, evitando las repeticiones obvias del actual escrito de interposición. En definitiva, la eliminación del escrito de preparación del recurso implicaría la supresión de un trámite procesal innecesario en la medida en que sus requisitos se cumplimentan en el escrito de interposición y, por supuesto, comportaría una evidente agilización procesal y un acortamiento de los plazos.

Significa esto que los requisitos estudiados en el epígrafe II del presente trabajo habrán de trasladarse mutatis mutandi al escrito de interposición -que, además, habrá de atender a sus propias exigencias (las estudiadas en el epígrafe III) - y, ello, con la innegable ventaja para el recurrente de haberse ampliado el plazo, pues se ha suprimido el brevísimo plazo de cinco días del actual escrito de preparación y la interposición del recurso ha pasado de vente a treinta días contados desde el siguiente al de la notificación de la sentencia (véase la reforma del artículo 479 de la LEC), que entendemos es un plazo suficiente para articular fundadamente la impugnación de la resolución recurrida.

En este sentido, en el escrito de interposición habrá de acreditarse el cumplimiento de los requisitos especiales previstos en el artículo 449 de la LEC para los juicios de desahucio, los de condena a indemnizar daños y perjuicios derivados de la circulación de vehículos de motor y los de reclamaciones debidas a las comunidades de vecinos, dada la modificación introducida al respecto por el Proyecto de Ley de medidas de agilización procesal. 
Asimismo y, como específicamente señala el nuevo artículo 481.1 de la LEC, en el escrito de interposición del recurso habrá de expresarse «el supuesto, de los previstos por el artículo 477.2, conforme al que se pretende recurrir la sentencia». Por tanto, casi con el mismo esfuerzo, el recurrente deberá en un mismo acto indicar la vía idónea de acceso a la casación y, además, fundamentarla y motivarla conforme a la interpretación dada al respecto en el Acuerdo del TS de 1212-2000 y que expusimos en el epígrafe I de este trabajo.

También en el escrito de interposición habrá de mencionarse y justificarse con la debida extensión, claridad y detalle la infracción legal sustantiva que se considere cometida, de acuerdo con la rigurosa «técnica casacional» a que hemos aludido en los epígrafes II y III del presente trabajo. Me atrevería a decir que quizá sea más fácil fundamentar el recurso, tal como se exige en la legalidad vigente y en el Proyecto de Ley en estudio (en el escrito de interposición), que sintetizarlo mediante la indicación sucinta pero detallada de la concreta infracción legal invocada (que es el objeto del actual escrito de preparación).

Pero, sin duda, donde más sentido tiene la supresión del escrito de preparación es cuando se pretenda acceder a la casación por la vía del «interés casacional», no en balde el TS, conforme a las directrices marcadas por el Acuerdo de 12-12-2000, ha venido exigiendo en el trámite de preparación razonamientos y justificaciones más propias de un escrito de interposición y que, por tanto, tendrían un mejor acomodo.

Lo que no podemos compartir con el Gobierno y su Proyecto de Ley de medidas de agilización procesal es el pretender elevar la summa gravaminis de 150.000 a 800.000 euros (véase la modificación introducida en el apartado 2 del artículo 477 LEC), dado que ello supondría en la práctica vetar el acceso a la casación de la gran mayoría de los litigios.

La Exposición de Motivos del referido Proyecto de Ley justifica dicha reforma "para que el Tribunal Supremo pueda cumplir de forma más eficaz los fines legalmente establecidos». Cierto que semejante disminución en el número de asuntos permitiría al TS resolver con mayor agilidad los recursos y que la función nomofiláctica de la casación no ha de proyectarse sobre cualesquiera sentencias y cuestiones. Mas no es menos cierto que con esta reforma se entorpecería aún más la función de creación y unificación de la Jurisprudencia que también es propia de la casación (ex artículos 9, 14, 24 y 123.1 de la 
Constitución), máxime teniendo en cuenta la rigurosísima interpretación dada al respecto en el tantas veces reiterado Acuerdo del TS de 12 de diciembre de 2000. Si, al menos, el Alto Tribunal permitiera combinar los distintos ordinales del artículo 477.2 de la LEC admitiendo el recurso en asuntos tramitados por razón de la cuantía que no excedieran de 800.000 euros pero en los que concurriera el «interés casacional», podríamos pensar que no estamos ante una justicia para ricos. 
